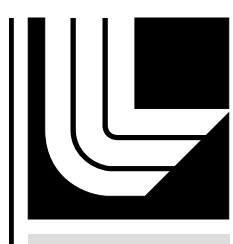

LAWRENCE LIVERMORE N A TIO NAL LABORATORY

Review of the Hatfield and Dawson RF assessment for Bechtel

R. J. Kane

October 12, 2011 
This document was prepared as an account of work sponsored by an agency of the United States government. Neither the United States government nor Lawrence Livermore National Security, LLC, nor any of their employees makes any warranty, expressed or implied, or assumes any legal liability or responsibility for the accuracy, completeness, or usefulness of any information, apparatus, product, or process disclosed, or represents that its use would not infringe privately owned rights. Reference herein to any specific commercial product, process, or service by trade name, trademark, manufacturer, or otherwise does not necessarily constitute or imply its endorsement, recommendation, or favoring by the United States government or Lawrence Livermore National Security, LLC. The views and opinions of authors expressed herein do not necessarily state or reflect those of the United States government or Lawrence Livermore National Security, LLC, and shall not be used for advertising or product endorsement purposes.

This work performed under the auspices of the U.S. Department of Energy by Lawrence Livermore National Laboratory under Contract DE-AC52-07NA27344. 


\section{REVIEW OF THE HATFIELD AND DAWSON ASSESSMENT FOR BECHTEL}

Ron Kane

Engineering / NSED

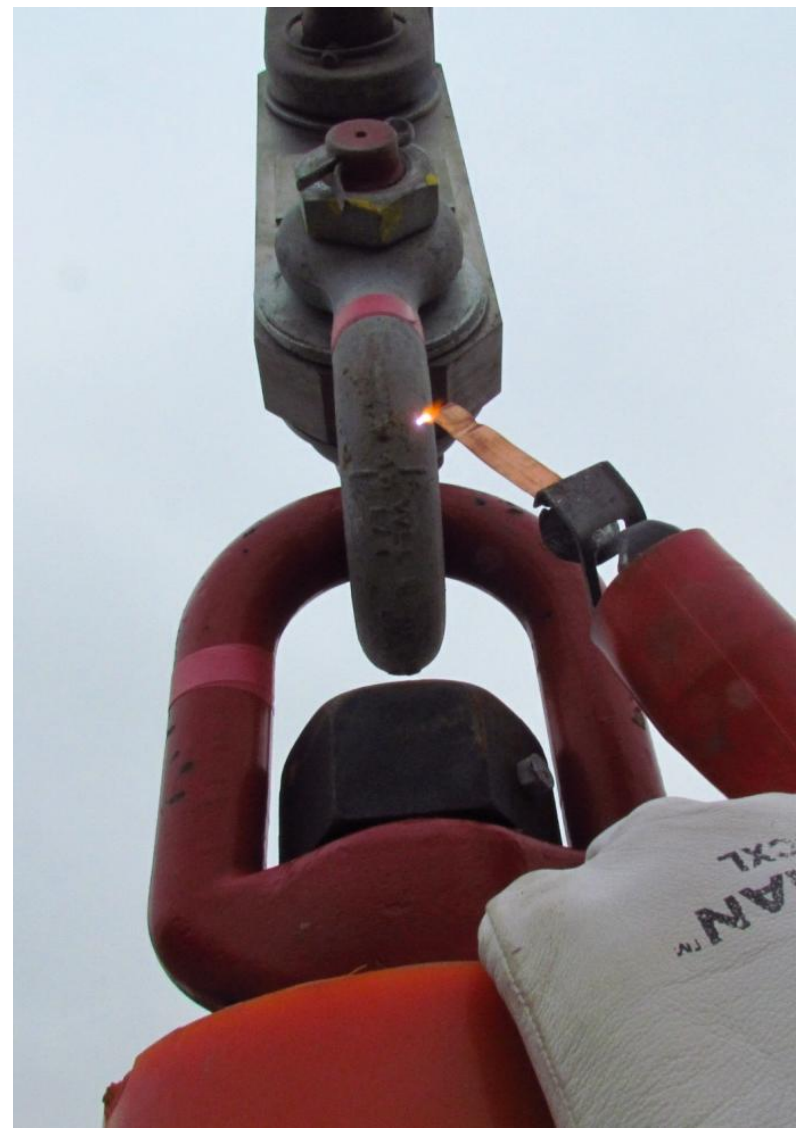

Lawrence Livermore National Laboratory is operated by Lawrence Livermore National Security, LLC, for the U.S. Department of Energy, National Nuclear Security Administration under Contract DE-AC52-07NA27344. 
LLNL-TR-504991

\section{DISCLAIMER}

This document was prepared as an account of work sponsored by an agency of the United States government. Neither the United States government nor Lawrence Livermore National Security, LLC, nor any of their employees makes any warranty, expressed or implied, or assumes any legal liability or responsibility for the accuracy, completeness, or usefulness of any information, apparatus, product, or process disclosed, or represents that its use would not infringe privately owned rights. Reference herein to any specific commercial product, process, or service by trade name, trademark, manufacturer, or otherwise does not necessarily constitute or imply its endorsement, recommendation, or favoring by the United States government or Lawrence Livermore National Security, LLC. The views and opinions of authors expressed herein do not necessarily state or reflect those of the United States government or Lawrence Livermore National Security, LLC, and shall not be used for advertising or product endorsement purposes. 


\section{EXECUTIVE SUMMARY}

The construction project at the Russell City Energy Center (RCEC) in Hayward, CA encountered a complication due to RF induction into the construction cranes resulting from operation of the two AM broadcast systems located immediately south of the site. The consulting firm Hatfield and Dawson was contacted by Bechtel for the assessment and mitigation of the induced currents and voltages and their recommendations were implemented by Bechtel. The staff at the Lawrence Livermore National Laboratory (LLNL) was subsequently asked to review the analysis of the Hatfield and Dawson work, provide an independent assessment and offer further mitigation comments.

LLNL has examined the work by Hatfield and Dawson, the numerical analyses of both agrees and correlates well with local field measurements. The mitigation efforts follow the OSHA rules and have been adapted to further reduce the possibility of worker injury through specialized training, daily task planning and specific assignments to workers to minimize exposure of all to the induced RF currents. LLNL further recommends that Bechtel formalize the RF training to provide additional value to the individual workers as well as for Bechtel to maintain documentation so that future work could make use of experienced workers.

There is a possibility that the RF energy will couple into the actuator and sensors as the facility is built out. The operation of the two transmitters could introduce interference formed from the interaction of the signals in nonlinear circuit responses producing intermodulation distortion. The result is interference at unexpected frequencies, some of which can be low and not filtered out of the sensors unless specifically identified. Future testing is planned for evaluating the likelihood for RF interference issues. 


\section{INTRODUCTION AND DISCUSSION OF TASKS}

Bechtel Corporation is constructing a natural gas-fed turbine generator system for power generation in the Russell City district of Hayward, CA. At the start of construction operations involving the use of tall cranes resulted in arcing as metal loads were attached and detached. The arcing is caused by induction of energy from an AM radio broadcast antenna array located to the SE of the Bechtel site. Radio frequency (RF) current being induced in the crane and cable structures near AM broadcast antennas has been published in other construction projects but general awareness by project managers and crane operators themselves is not widespread.

The consulting engineering firm, Hatfield and Dawson (Seattle, WA), was contracted with for the assessment of the issue and recommendation of mitigation techniques. Two reports were produced by Hatfield and Dawson in which the induced current phenomena and the impact of the facility on the AM broadcaster were discussed. The assessments of the consulting engineers was that use of the Hirtzer ${ }^{1}$ insulated link, non-conductive slings and use of gloves would mitigate induced currents, possible shock sensation and worker surprise. These steps are consistent with OSHA requirements and have been used at other construction efforts. ${ }^{2}$

Bechtel, a major member of the limited liability corporation that manages LLNL, contacted their LLNL office for possibly making use of LLNL technical expertise. The inquiry has led to a technical review of the Hatfield and Dawson work using both the personnel and tools available within LLNL. The specific tasks are:

1. An independent validation of the analysis performed to date,

2. A review of the current mitigation techniques and suggestions for improved approaches if any,

3. Review of the consultant's analysis of the impact of the broadcast facility on the power plant cabling and instrumentation

The effort undertaken by LLNL was not to repeat the work done by Hatfield and Dawson, rather, it's a comparison of the basic modeling codes to ensure that the computational assessments are reasonably matched. LLNL uses analysis codes based on the same physics methodology and differences will be due to user-selected parameters and assumptions in the setting up the model to be analyzed.

Two radio stations are involved, $\operatorname{KFAX}(1100 \mathrm{kHz})$ operates 24/7 transmitting at $50 \mathrm{~kW}$ from the four antenna element array adjacent to the Bechtel construction site; KTRB ( $860 \mathrm{kHz}$ ) is also $50 \mathrm{~kW}$ but uses only one of the four towers during the day to create an essentially omni-directional pattern, night time operations are from a separate broadcast facility located approximately 20 miles ESE and has no influence. The analysis in this report uses only one of the transmitters - KFAX. The KFAX operating frequency is higher and the RF wavelength is also slightly shorter than that of KTRB but this is negligible for the issues to be discussed. Our analysis also uses only the KFAX transmitter parameters to enable comparison to the work performed by Hatfield and Dawson for antenna radiation patterns, the addition of KTRB will double the instantaneous peak voltage when the RF waveforms are constructive but this is also not an important parameter because the main issue is the mitigation of induced RF currents and the impact on worker safety and construction operations. The comparison of the analysis techniques is discussed first and is followed by discussion of mitigation.

\section{COMPARISON OF MININEC AND FEKO COMPUTATIONAL TOOLS}

The analysis of antennas and their interactions with structures and the earth require solution of integral equations. Complex problems are solved using numerical techniques to approximate the integrals and one common approach is the "method of moments" (MoM). 
The MoM technique uses a linear wire or triangular patch and computes the electrical currents in the edges that are then used to compute the electric and magnetic fields at locations specified by the user. One of the original MoM codes was the Numerical Electromagnetic Code (NEC) which has undergone years of development and diversion to other forms. MiniNEC was a diversion created for desktop IBM-PCs and has itself undergone enhancement as well as the addition of GUls to make model entry and evaluation easier. Hatfield and Dawson use MiniNEC Pro and the perfect electrical conductor (PEC) to define the ground plane beneath the antenna. Their use of MiniNEC is mainly limited to wires to approximate the facility and the power transmission towers, the PEC ground simplifies analysis and these simplifications are adequate for this problem. NEC-4 is the latest, developed at LLNL but now fairly old, a robust analysis code capable of handling complex air-earth interfaces as a real ground, this code is maintained and provided to users by LLNL staff for a modest fee.

FEKO is also a MoM code but has more features than NEC-4 and a GUI that aids in setting up the problem and viewing the results, it is an expensive code however and is shared by a number of users at LLNL. Both MiniNEC and FEKO agree when used to compute the FCC reference antenna pattern for KFAX licensing.

The reference radiation pattern is specified by the FCC at a distance of $1 \mathrm{~km}(\sim 3280 \mathrm{ft})$. The Hadfield and Dawson work included the estimation of the antenna source parameters (voltages and phases) based on the FCC specification of the 'antenna factors'. The Hatfield and Dawson results reproduce the reference (FCC) antenna pattern and we too have used these source parameters as input and reproduce the same shape using a different MoM code. In all cases either a perfect ground plane or a least a very conductive ground are assumed. The three antenna pattern estimates are:

- $\quad$ FCC reference

- Hatfield \& Dawson

- $\quad$ LLNL
$3.73 \mathrm{~V} / \mathrm{m}$ at $1 \mathrm{~km}$

3.7 V/m, approx. From H\&D Phase 2 report, 6/2011, page $73 .{ }^{3}$

$3.72 \mathrm{~V} / \mathrm{m}$

Figures $1-7$ show the FCC reference plot, Hatfield and Dawson's MiniNEC results and the results of the LLNL analysis using the code FEKO. The 3-d plots from FEKO are used so that the elevation properties of the radiation pattern are apparent.

The choice of ground parameters is one area where the computer analyses will differ. The FCC regional estimate for soil conductivity in the San Francisco Bay area is $15 \mathrm{mS} / \mathrm{m}$, this is fairly conductive but the use of the PEC ground plane appears be adequate for the Hatfield and Dawson assessment. FEKO has been used with an estimate for the ground as well as metallic ground planes at the base of the antenna array. Simulations used metallic ground planes of rectangular and circular shape and positioned above the ground to reduce the computational complexity. The actual site probably has a limited, buried ground plane and with limited extent because of the closeness of the neighboring properties.

Use of a PEC ground will maximize the fields near the surface and represents the conservative approach. Real grounds have been used to determine if significant sensitivities exist and are more readily computed with faster computers. The difference between the PEC and real grounds is relatively small in the modeling of this situation, a comparison is listed in table 1. 
Table 1. Field estimates using FEKO for modeling the KFAX Fields

\begin{tabular}{|c|c|c|c|c|}
\hline Ground Model & Ground Plane Shape & Distance & $\begin{array}{c}\text { E-Field } \\
\text { at Surface }\end{array}$ & $\begin{array}{c}\text { E-Field @ } \\
20^{\circ} \text { Elevation }\end{array}$ \\
\hline Perfect (PEC) & Full space & $\sim 1 \mathrm{~km}(3200 \mathrm{ft})$ & $3.7 \mathrm{~V} / \mathrm{m}$ & $3.0 \mathrm{~V} / \mathrm{m}$ \\
\hline $\begin{array}{c}\text { Real 15 S/m } \\
\text { (FCC estimate) }\end{array}$ & $\begin{array}{c}\text { Rectangular } \\
\text { patch }\end{array}$ & $\sim 1 \mathrm{~km}$ & $1.9 \mathrm{~V} / \mathrm{m}$ & $3.7 \mathrm{~V} / \mathrm{m}$ \\
\hline $\begin{array}{c}\text { Real 30 S/m } \\
\text { (Very good ground) }\end{array}$ & $\begin{array}{c}\text { Rectangular } \\
\text { patch }\end{array}$ & $\sim 1 \mathrm{~km}$ & $2.3 \mathrm{~V} / \mathrm{m}$ & $2.4 \mathrm{~V} / \mathrm{m}$ \\
\hline Real 15 S/m & Disc & $\sim 1 \mathrm{~km}$ & $1.5 \mathrm{~V} / \mathrm{m}$ & --- \\
\hline Real 15 S/m & Disc & $800 \mathrm{feet}$ & $9.7 \mathrm{~V} / \mathrm{m}$ & --- \\
\hline $\begin{array}{l}\text { H\&D PR-906 } \\
\text { Measurement }\end{array}$ & --- & $748 \mathrm{feet}$ & $10 \mathrm{~V} / \mathrm{m}$ & \\
\hline
\end{tabular}

The purpose of this table is show that the estimated electric fields are generally within a factor of 3 or so when comparing models at the same height and distance; ranging from 3.7 to $1.5 \mathrm{~V} / \mathrm{m}$ at $1 \mathrm{~km}$. The effect of distance is apparent when compared to the $800 \mathrm{ft}$ distance, the fields scale as $1 / R$ in free space but near the real ground surface there is an added attenuation as the signal propagates, the $10 \mathrm{~V} / \mathrm{m}$ measured by Hatfield and Dawson correlates well (both KFAX and KTRB 'add'). ${ }^{4}$

The computational results and a few field measurements show reasonable correlation, since two different computer codes and a variation in ground plane treatments show similar values the modeling treatment is demonstrated to be adequate. The details of the analysis in the Hatfield and Dawson reports should be the primary results referenced; Hatfield and Dawson are Registered Professional Engineers and are therefore recognized subject matter experts.

\section{CRANES AND StRUCTURES - INDUCED CURRENTS AND FIELDS}

The RF transmitted from the tower array propagates radially outward with mainly a vertically-polarized electric field and a horizontally-polarized magnetic field. The magnetic field can induce a current in a closed conducting loop following the Maxwell-Faraday law for induction. Since the AM broadcast transmission is continuous the current flow is also continuous. Opening the conductor loop will interrupt the current flow and an arc will result as has been observed during operations and demonstrated to us. The orientation of the plane of the loop to the local magnetic field also affects voltage and current that is induced. The orientation for maximum induced current is when the normal of the loop plane lies parallel to the magnetic field lines. The aperture of the loop determines how much can be coupled from the magnetic field; the larger the loop the higher the induced current. In a uniform magnetic field environment the area of the loop, not the shape, is the important factor. For this problem scenario the shape has some effect but is negligible for the most part since construction operations need to accommodate the existing situation rather than examine precise estimation of currents.

The construction site is within a wavelength of the operating frequencies for the AM transmitters, as such there will be a higher magnetic flux density in the direction of the towers. The field level shows broad spatial distribution but the worst case for induction is to present the largest loop aperture in the direction of the towers, i.e. using the crane with its metal rope and load pointed toward the antenna array. However, there is not much difference between the crane oriented toward the antennas versus the same location but facing away, both will induce enough current to result in arcing. 
The creation of an arc in a conducting loop that is broken is readily observed when working at this site. When a conductive loop with current flowing is broken a small arc will be created at the junction, the ionized air allows the electric potential across the gap to remain small and the distance between the ends of the conductive loop can be pulled apart some distance before it extinguishes. Personnel injury - RF burns, worker surprise, ignition of flammable vapors and other materials are a concern.

Simulation of the current that would flow through a human analog ( $400 \Omega$ body resistance) touching the hook from a 200 foot boom at $45^{\circ}$ elevation angle resulted in a current estimate of $1.2 \mathrm{~A}$, Mr. Ford has measured $1.5 \mathrm{~A}$ during the daily surveillance measurements. There could be a difference of a few hundred feet between the real and simulated measurements and loop area changes will also affect the current magnitude as well but this is very good agreement.

\section{Personnel and Hazardous Operations Considerations}

The creation of an arc while working with a crane was apparently the trigger for the assessment performed by Hatfield and Dawson. We (Kane and O'Brien) visited the site on August 3 to get oriented and Mr. Russell Ford gave us an orientation tour and demonstration of the RF coupling to a crane. A photograph demonstrating how an arc can be drawn from the Liebherr crane is included as Figure 11 in the appendix.

The main concern is for the safety of the personnel. While walking the site we were impressed by the administrative measures; the procedures, operations and attention given to safety, eye contact being paramount. Work plans are also used daily with attention given to actions that are different than usual. The use of insulating links and the use of conducting straps are incorporated as engineered measures. Current operations appear consistent with OSHA rules as well. Ongoing worker education is necessary, especially as new crews are brought on site. The biological effects of low frequency EM fields are discussed as well, RF fields remain inconclusive with regard to cancers which is a good thing; there is no proof of a direct correlation however and proving that there is no connection is impossible (the null case).

Worker training includes a demonstration of the creation of an arc to emphasize the issue, the workers require enough training and knowledge so that they recognize the situations in which a coupled loop is created and what conductors could have currents or voltages present. We have suggested to Mr. Ford that the training be formalized so that workers can receive recognition for this specialized work and as an opportunity for Bechtel to be able to select workers for future work where RF transmitters may be again involved. The content of the training materials was not reviewed but these should include details that point out the differences between the commonly encountered $60 \mathrm{~Hz}$ power frequencies and that of the medium wave RF frequencies for the AM broadcast towers. The RF hazard includes surprise, tingling sensations and RF burns that result from surface and deeper tissue heating.

The construction crews use non-conductive tag lines and grounded clamps as loads or elevated crane hooks are maneuvered, a conductive "sacrificial" grounding connection is also used to control where arcs will occur to prevent arcing on structural assemblies of the plant itself. A similar situation involving helicopter operations with suspended loads requires a crewmember with the assignment of grounding the triboelectric charge that builds up during flight, this is the 'hook man' who has the training and experience to know what is safe and unsafe. More recent email exchanges with Mr. Ford suggested that Bechtel workers have evolved to load handling in manner similar to the hook man operations in recognition that the specific assignments protect the other workers. 


\section{MitigATION DISCUSSION}

The Hatfield and Dawson report recommended the use of insulated links, non-conductive rope and non-conductive slings. The use of the Hirtzer insulated links and non-conductive slings were observed during our site visit. These insulators isolate the loads from the crane assembly that may create most of the conductive loop of concern. Cranes that have metal track structures in contact with the ground and through the boom are safe for the crew operating the crane but are a hazard for the ground crew working with the hook. The isolating links separate the load from the crane conductive loop and act as reminders for the workers to keep away from the hook end conductor. The hook man equivalent is a necessary function when contact with the crane cable and its termination is required.

An intentional chassis grounding connection may be required when smaller cranes with wheels or others on surfaces that may be more insulated than being directly on the ground are used. This situation presents an issue to the operator boarding the crane if it has a conductive loop through a load on the ground. This is a reflection of the normal crane and load configuration where the load and cable form the conductive loop and the insulated crane body is the area where the potential difference is developed. Smaller cranes may not use the insulated links as rigorously and placing the load on the ground and dismounting the crane may not be unusual but operations at the staging yard close to the antenna array should be observed for possible arcing issues.

OSHA rule 1926.1501(a)(15)(vii)(a) [see the Endnotes] requires grounding of the chassis and this is generally the safer practice for the crew operating the vehicle. Rule (b), in the same section, states that the load should be grounded but this would ensure a complete loop complicating disconnect operations. This rule fails to take into account the insulating link now used to isolate the load, the "hot" end of the cable requires specific attention but the insulated load is less of an electrical hazard. There is a new rule is in use for power line safety and insulating links are required as well as voltage-rated gloves, this rule has application to working near an AM broadcast station based on voltages and currents flowing but without the benefit of a line fault detector system that should stop the energy source. [See power line safety in section 1926.1407-1411]

The use of insulated links are to protect workers from the hot ends of conductive loops. The shape of the loads must also be considered when the load dimension also approximates a loop, the large roof truss is an example. While the load is likely to be supported using insulated slings the load itself can create an inductive loop when in the vertical plane, a voltage could be created at one of the ends when the other end is grounded. Orientation and distance from the antenna array also affect the magnitude of the voltage generated at the end and the possible current flow.

\section{OPERATIONS}

As the facility is built out it will include remote monitor and control instrumentation. The coupling of RF energy into these circuits and sensors was a concern due to a lack of knowledge of what actuators and sensors are used and where they are located. Controls and sensor wiring is expected to be closely-spaced pairs, preferably twisted as well and multi-conductor cables may have additional shielding. Cables are expected to be routed in metal conduit providing additional protection.

Hatfield and Dawson make reference to the International Electrotechnical Commission (IEC) standards for electronic product immunity and compatibility and state a $3 \mathrm{~V} / \mathrm{m}$ minimum tolerance. A more appropriate standard would be IEC 61000-4-3 (2006), Annex E.2 Class 3 specifying tolerance to $10 \mathrm{~V} / \mathrm{m}$ where the environment 
is that of an industrial setting. ANSI C63.12-1999 uses the same field level and references IEC 61000-4-3 so there is some consistency developing between the US and European suppliers and applications.

The AM broadcast facility has two $50 \mathrm{~kW}$ transmitters operating during daytime hours. This configuration increases the electric and magnetic field levels in the RCEC facility and can give rise to other effects due to the interaction of the signals from the transmitters within some electronics. When a strong RF signal is coupled into electronics the circuit can experience non-linearity or saturation effects, these can result in the creation of RF signal harmonics. When there are two signals interacting in a non-linear circuit then intermodulation distortion (IMD) can occur and the sum and difference frequencies are produced in the circuit. There is the potential that interfering signals will exist as shown in the following table.

Table 2. Possible interference frequencies

\begin{tabular}{|l|l|l|}
\hline Frequency & Source & Comment \\
\hline $240 \mathrm{kHz}$ & Intermodulation difference frequency & May be within sensor bandwidths \\
\hline $860 \mathrm{kHz}$ & KTRB transmit frequency & Strong interaction \\
\hline $1100 \mathrm{kHz}$ & KFAX transmit frequency & Strong interaction \\
\hline $1720 \mathrm{kHz}$ & KTRB second harmonic - induced in circuits & \\
\hline $1960 \mathrm{kHz}$ & Intermodulation sum frequency & Also consider 2 (F1) -( F2) =610 kHz... others. \\
\hline $2200 \mathrm{kHz}$ & KFAX Second harmonic - induced & \\
\hline
\end{tabular}

A spectrum analyzer would be useful for assessing the frequency content present on sensor and actuator cabling as well as the impact on power supplies. The design of the actuators and sensors for industrial applications usually include well-grounded housings and the cables will be in conduit or within cable raceways so the AM broadcast station energy should be shielded. A facility staff member should be versed in the use of spectrum analysis techniques and electromagnetic compliance issues to minimize subsystem down time should interference develop.

\section{CONCLUSIONS}

The tasks required by Bechtel for this work were the independent assessment of the reports provided by the consultants Hatfield and Dawson, a review of the mitigation techniques and consideration for the impact on the controls used at RCEC. The first two tasks are complete, the third task has been commented on but issues with the sensors and controls will be dependent on the construction activity.

The analysis work performed by Hatfield and Dawson using the MiniNEC Pro software agrees with similar analysis where the computer code FEKO has been used. These codes use the same underlying numerical techniques and differ in treatment of the ground conditions and ease of use. The computer approximations and local measurements agree bounding the results.

The mitigation techniques are now covered by OSHA requirements, the rules apply mainly to power transmission facilities but reference is also made to broadcast facilities. Bechtel's construction work follows these rules and supersedes them through the practices of assigning specific workers to the load handling tasks and the daily rigor of assessing work that may be impacted by RF coupling.

Industrial practices for installing actuators and sensors and routing cables is expected to be adequate for operations and prevent RF interference. Tests are planned at a later date to verify that this assumption is correct. Unshielded wire extending from conduits or laying outside of raceways is expected to be the entry point for interference, minimizing the amount of such wiring is expected. 


\section{REFERENCES}

Bechtel provided facility drawings, schedule information as well as a significant number of photographs from representative facilities to orient the LLNL staff with the type of construction efforts involved. Other resources include:

“Initial Report, RF Environment of the Russell City Energy Center Site”, Hatfield and Dawson, March 2011.

"Phase Two, Russell City Energy Center Radio Frequency Environment Effects on Construction Activities", Hatfield and Dawson, June 2011.

"Interaction of a MW AM Broadcast Transmitter with a Large Crane and the Analysis of Workers' Safety", Fatih Ustuner, IEEE paper 978-1-4244-5118-0/11.

"A case study of induced body currents on 110 kV lines due to an adjacent AM radio site", Brett Moule, Kordia Solutions, EMF Scientific Workshop, 23 Nov 2010.

\section{OSHA REgULATION EXTRACTIONS}

Two sections of the OSHA regulations apply in concept. Section 1408 is used in construction while section 1501 is referenced for demolition and underground construction, these precautions are required although the use of insulating links to the loads is not referenced. The use of insulating links for use near power lines is a recent introduction to this type of work.

1926.1408(f)

When working near transmitter/communication towers where the equipment is close enough for an electrical charge to be induced in the equipment or materials being handled, the transmitter must be deenergized or the following precautions must be taken:

1926.1408(f)(1)

The equipment must be provided with an electrical ground.

1926.1408(f)(2)

If tag lines are used, they must be non-conductive.

There is more ground connection detail in Section 1501 that applies to any work in the vicinity of AM Broadcast towers:

\subsection{1(a)(15)(vi)}

Any overhead wire shall be considered to be an energized line unless and until the person owning such line or the electrical utility authorities indicate that it is not an energized line and it has been visibly grounded;

\subsection{1(a)(15)(vii)}

Prior to work near transmitter towers where an electrical charge can be induced in the equipment or materials being handled, the transmitter shall be de-energized or tests shall be made to determine if electrical charge is induced on the crane. The following precautions shall be taken when necessary to dissipate induced voltages: 
1926.1501(a)(15)(vii)(a)

The equipment shall be provided with an electrical ground directly to the upper rotating structure supporting the boom; and

\subsection{1(a)(15)(vii)(b)}

Ground jumper cables shall be attached to materials being handled by boom equipment when electrical charge is induced while working near energized transmitters. Crews shall be provided with nonconductive poles having large alligator clips or other similar protection to attach the ground cable to the load.

\subsection{1(a)(15)(vii)(c)}

Combustible and flammable materials shall be removed from the immediate area prior to operations.

\subsection{1(a)(16)}

No modifications or additions which affect the capacity or safe operation of the equipment shall be made by the employer without the manufacturer's written approval. If such modifications or changes are made, the capacity, operation, and maintenance instruction plates, tags, or decals, shall be changed accordingly. In no case shall the original safety factor of the equipment be reduced.

Note that the Federal Register includes references to operational safety in the vicinity of transmitter towers, these are essentially the same as the OSHA requirements but are generally applied to crane operations. 
LLNL-TR-504991

\section{FIGURES}

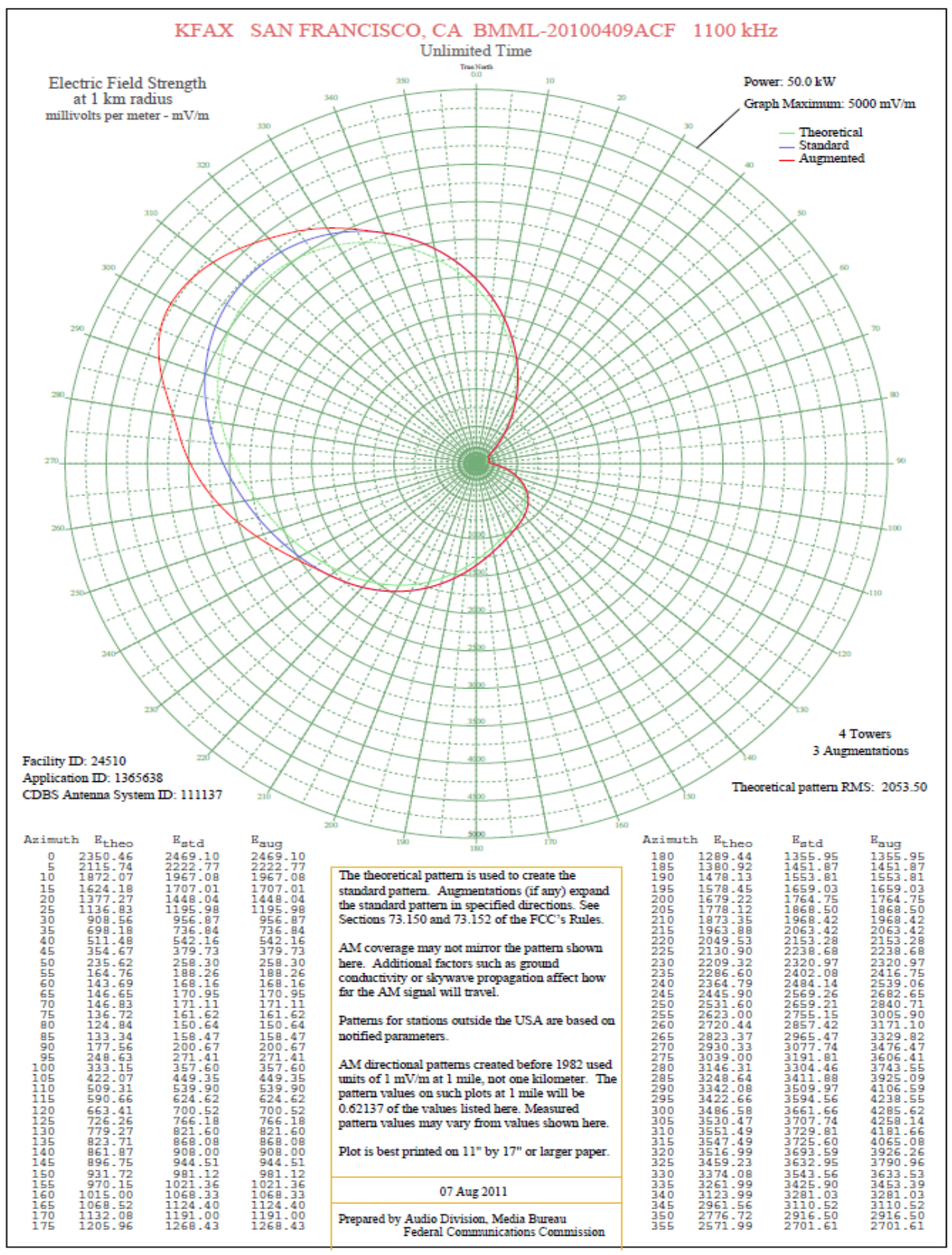

Figure 1-FCC Reference Broadcast Pattern 


\section{RCEC MININEC Model for KFAX \& KTRB}

\section{KFAX Theoretical Pattern}

Fleld Strength $\mathrm{mV} / \mathrm{m}$ at $1 \mathrm{~km}$

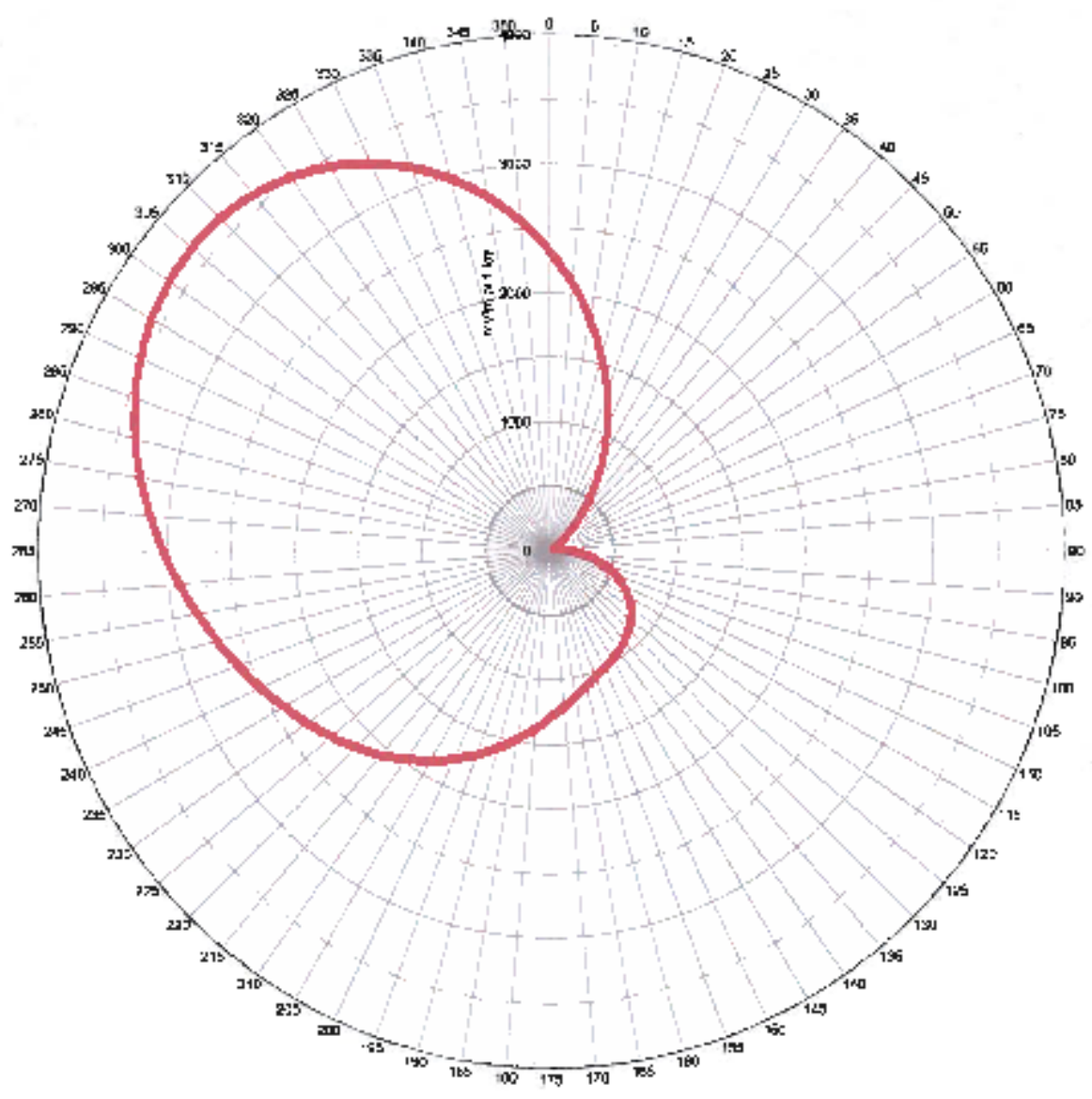

I Tatfield \& Dawson Consulting Engineers

Figure 2. Hatfield and Dawson Reference Pattern Plot

The peak value and angle are consistent with the FCC standard radiation plot.

The peak field is about $310^{\circ}$ and $3.73 \mathrm{~V} / \mathrm{m}$. 


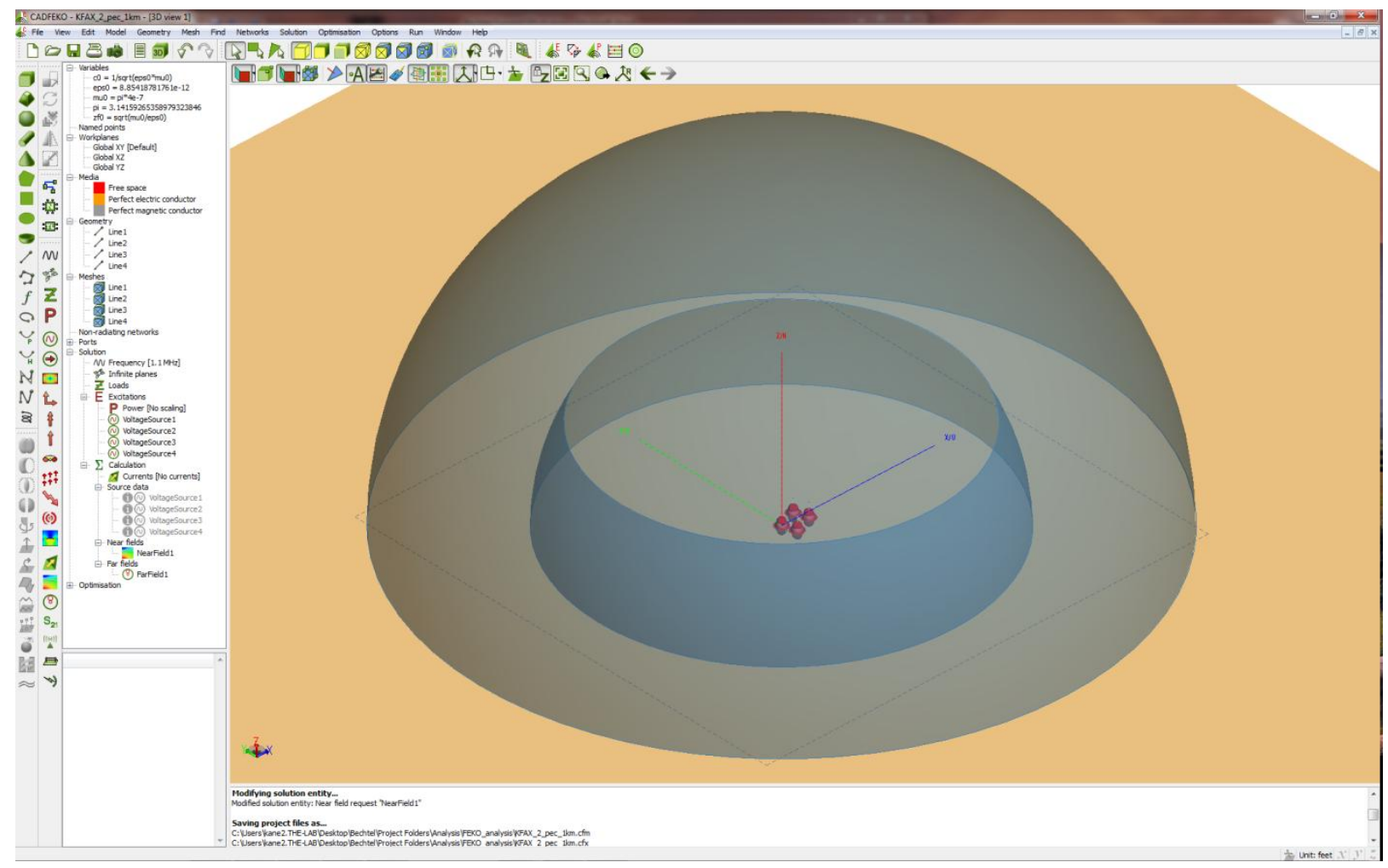

Figure 3. Work environment for the FEKO Analysis Code

Screen shot of the PEC boundaries - near-field / far-field and PEC ground plane. Antennas are shown in small format as the 4 small red objects and north is along the green axis line (y axis) 


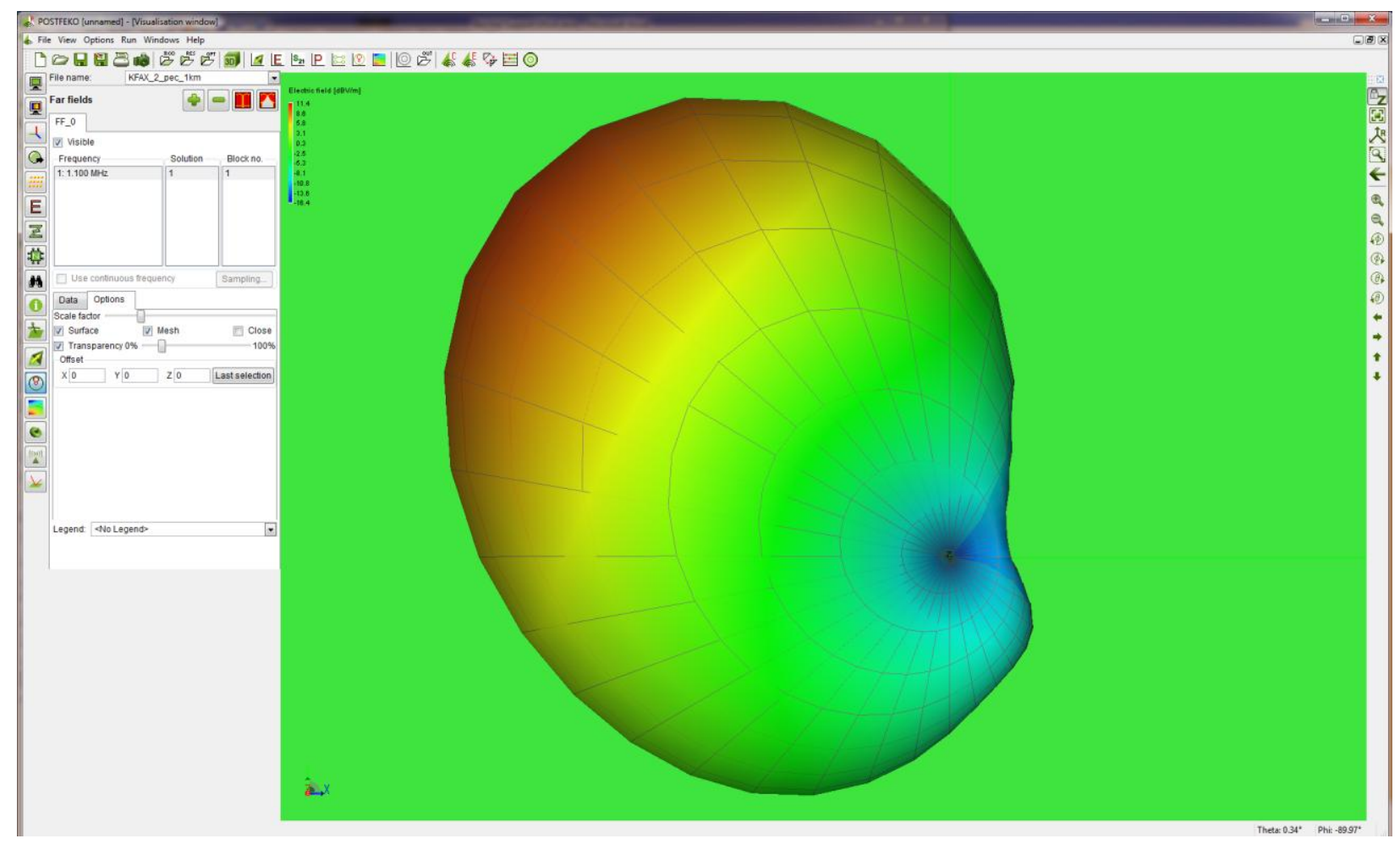

Figure 4. E-field pattern looking down on the antenna array.

This is the far field pattern which is similar to the fixed distance near-field plots. The pattern null is shown as the blue region close to the axis and is actually underneath the main pattern. North is UP. 


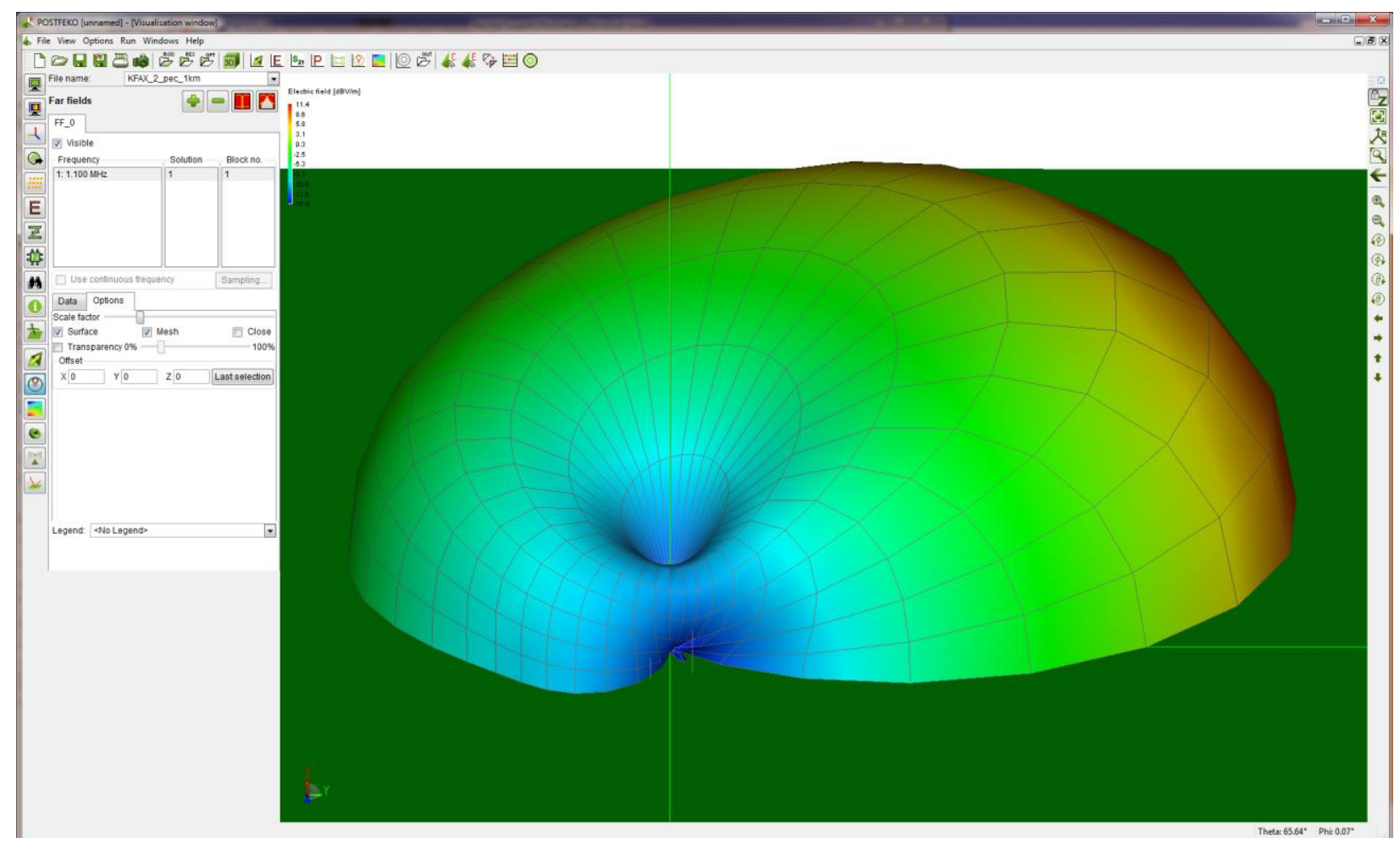

Figure 5. Looking into the null region, directly west. 


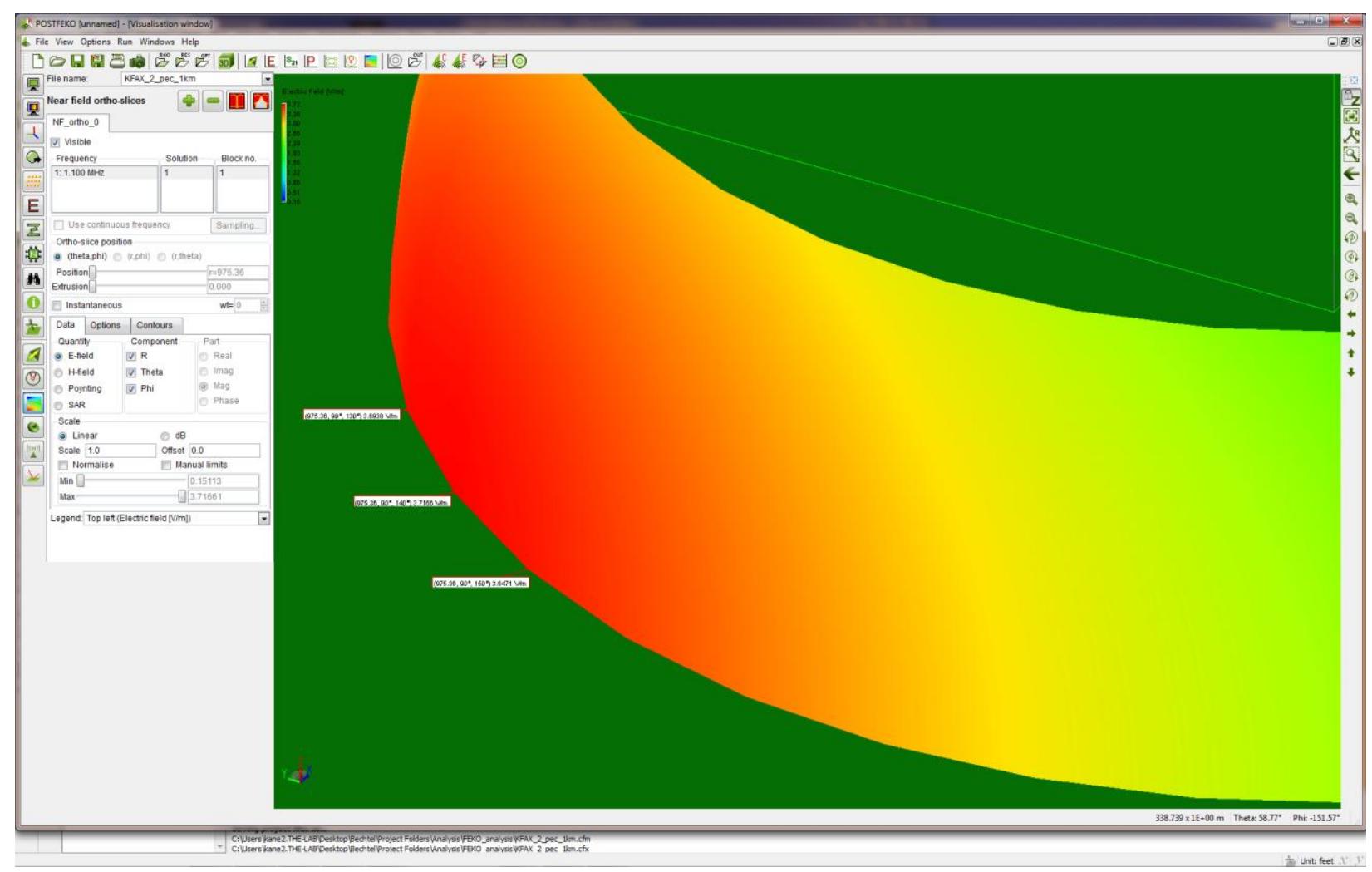

Figure 6. Ground level, near-field values are highlighted.

The value here is $3.7 \mathrm{~V} / \mathrm{m}$, in the FCC documentation it's within a few tenths of a volt, as well as in the Hatfield and Dawson result from page 73 - KFAX theoretical estimates, H\&D Engineering Report Phase Two, 6/2011. The axes are different - this one goes CCW from ' $x$ ' to $140^{\circ}$, the FCC and H\&D plots start with $0^{\circ}$ north and go CW around to $310^{\circ}$ to reach the same point. 


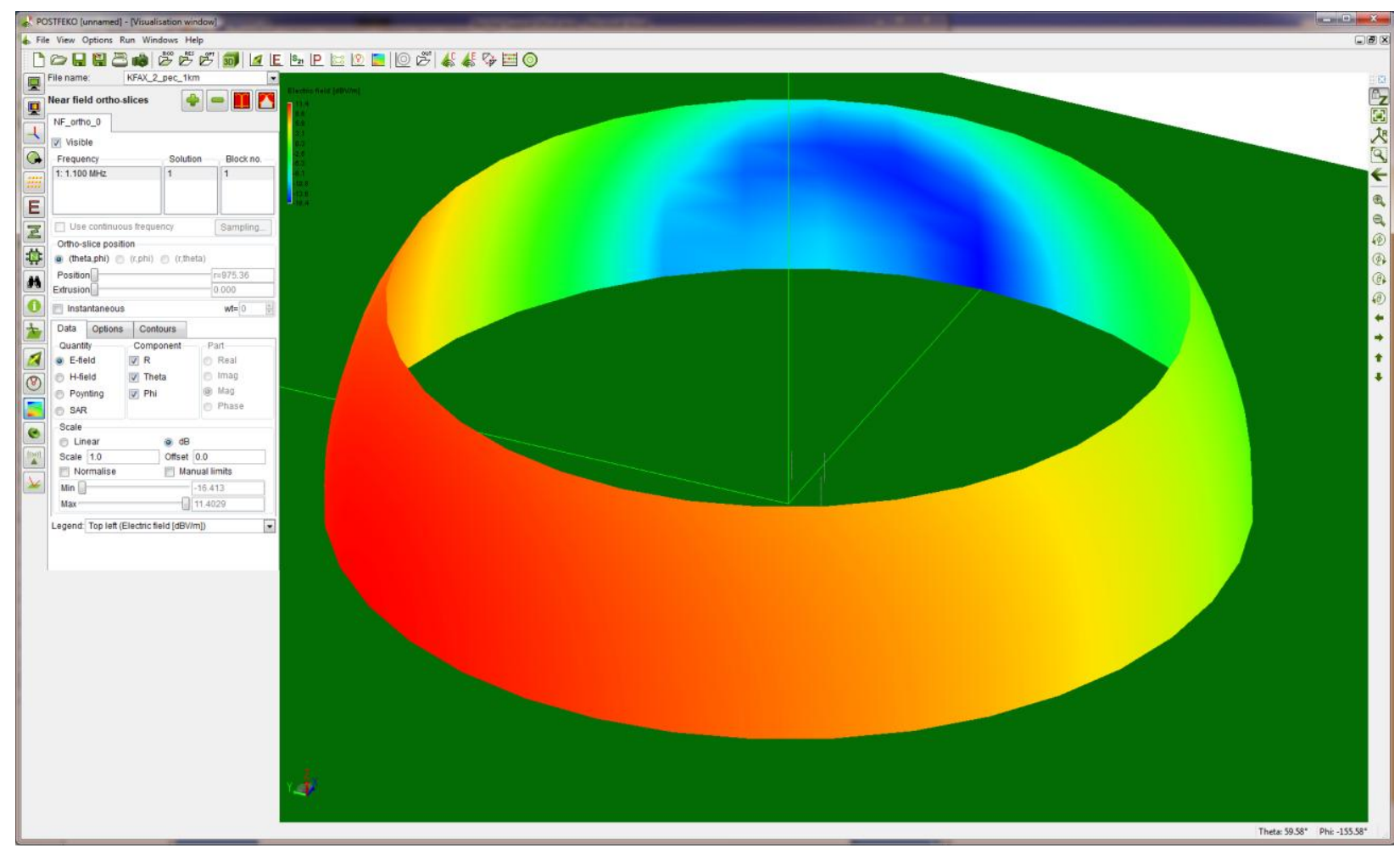

Figure 7. The broad red area corresponds to the main radiation pattern region.

North is the axis to the left resulting in the pattern minimum being directed ENE where the blue field is shown. 


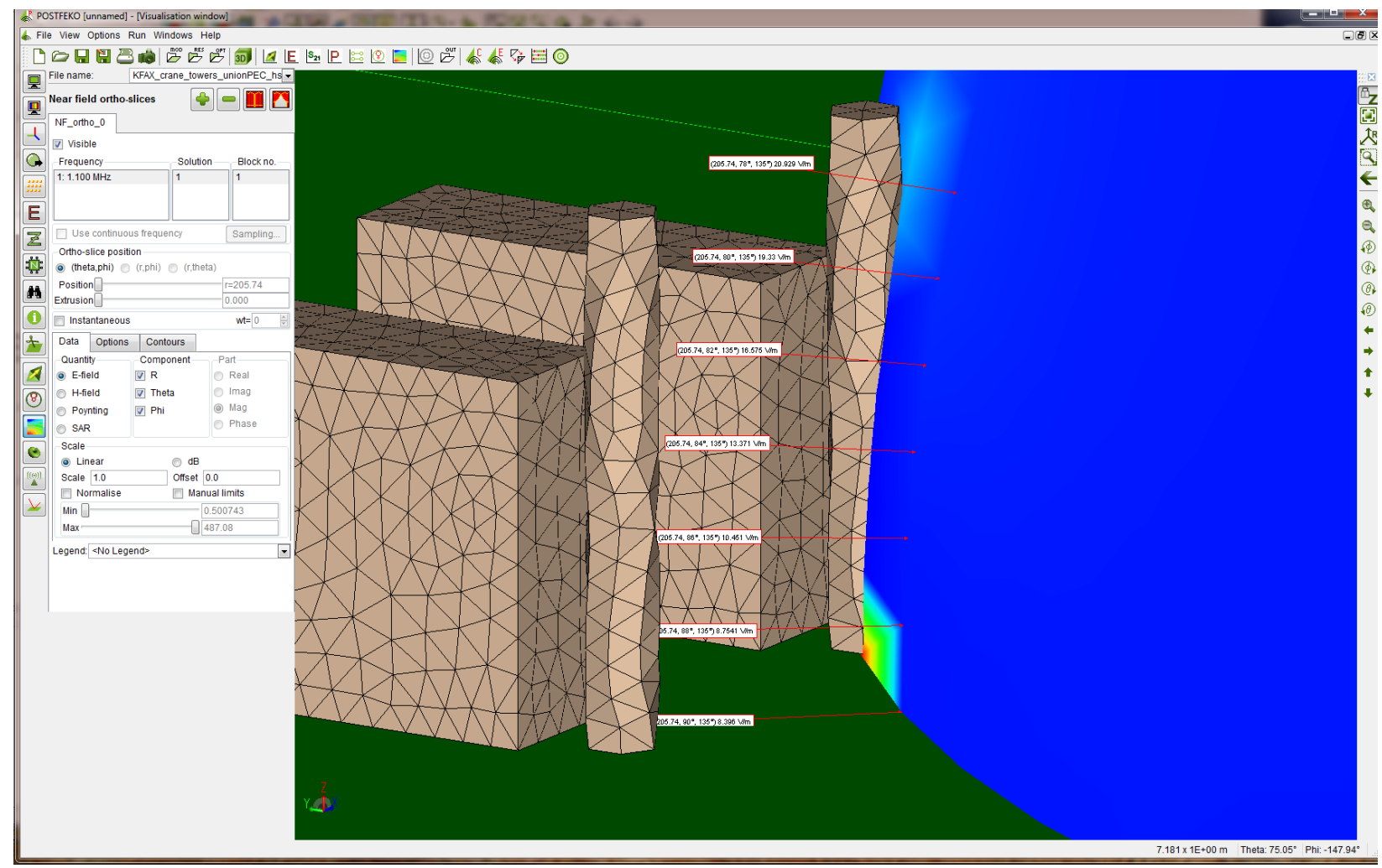

Figure 8. E-Field estimates in the vicinity of the HSRG Structures.

Electric field values in the immediate vicinity of the closest structure suggest that localized fields can range from $\sim 10 \mathrm{~V} / \mathrm{m}$ near the ground to $20 \mathrm{~V} / \mathrm{m}$ near the highest portions of the structure. The structure itself will also tend to shape fields resulting in concentration of the fields in some areas. 


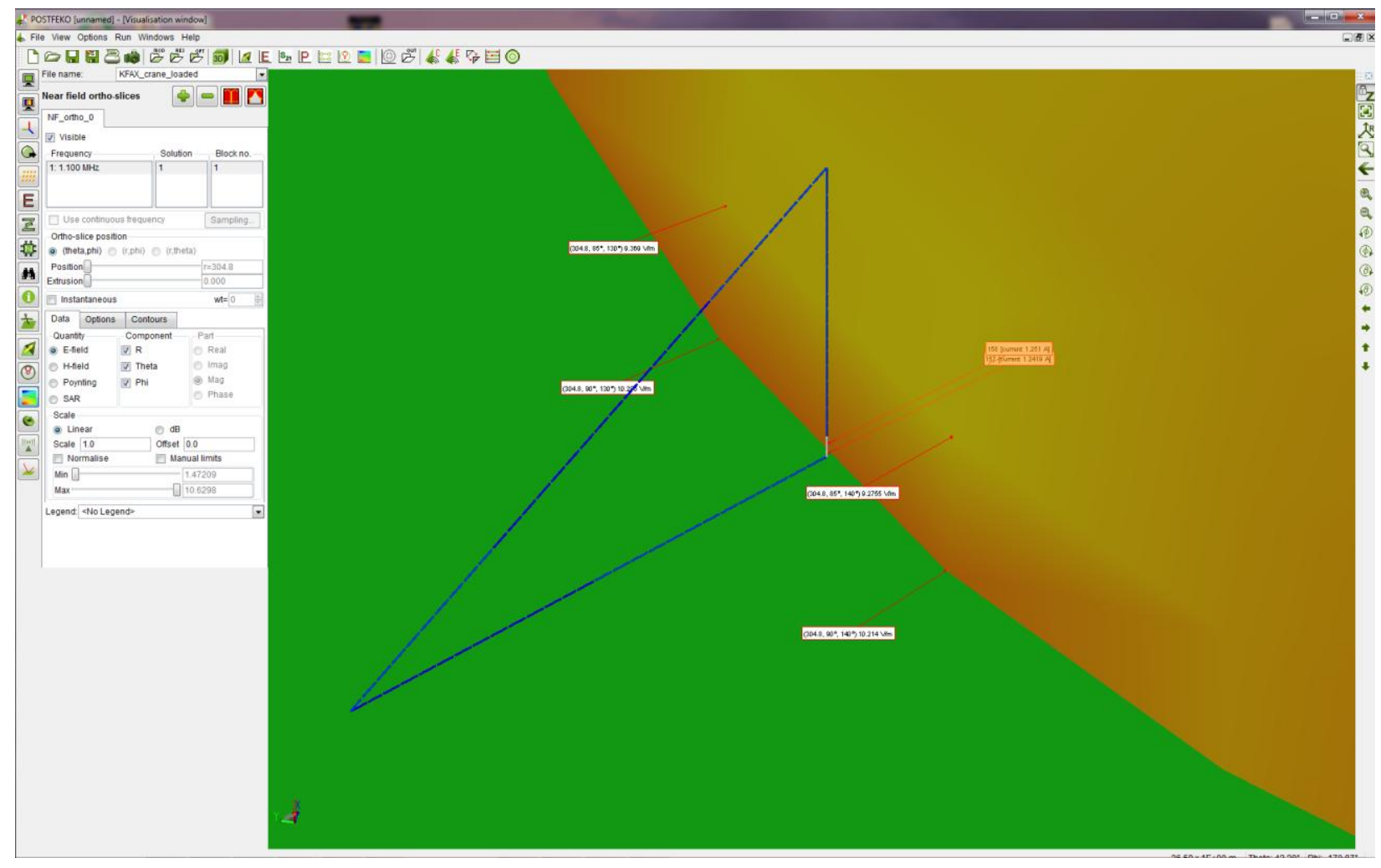

Figure 9. Current estimate at the crane hook with a $430 \mathrm{Ohm}$ load - $1.2 \mathrm{~A}$

The crane location is approximately $1000 \mathrm{ft}$ from the broadcast array with a boom peak height at $194 \mathrm{ft}$. 


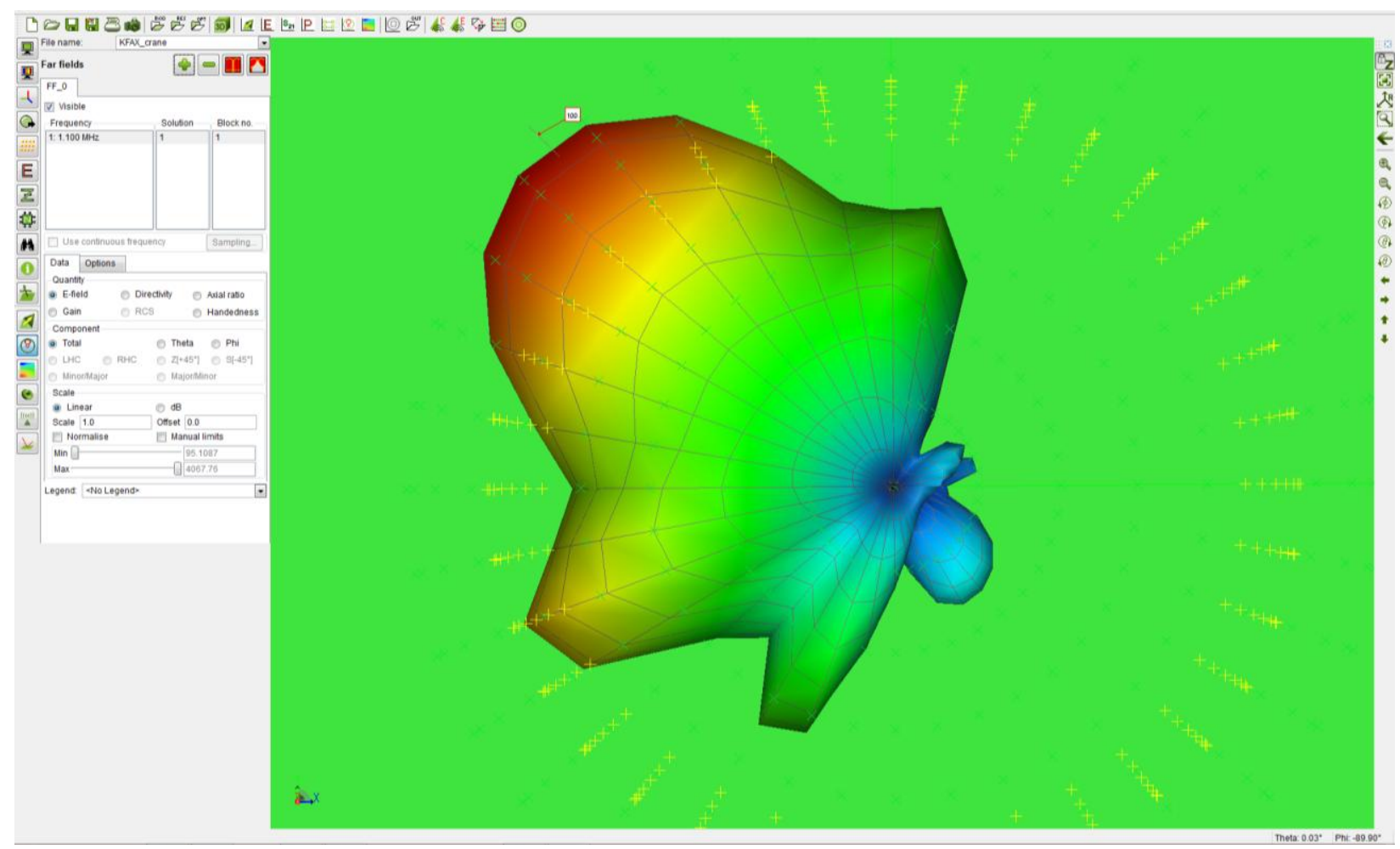

Figure 10. Broadcast antenna far field radiation pattern

The radiation pattern at distances of miles was computed to evaluate deviation from the near field approximation specified by the FCC application. The simulation shown uses a circular ground plane and good ground conductivity, the general pattern characteristics follow that of the reference pattern where there is a lobe to the northwest and a reduced intensity toward the east and southeast. This simulation does not account for other objects - the PG\&E towers and nearby buildings, the far field pattern will retain this general shape but may have more peak and null variation but there would be little impact on the customer base for KFAX and KTRB. A simple repositioning of the receiver antenna is the expected action on the part of the customer. 


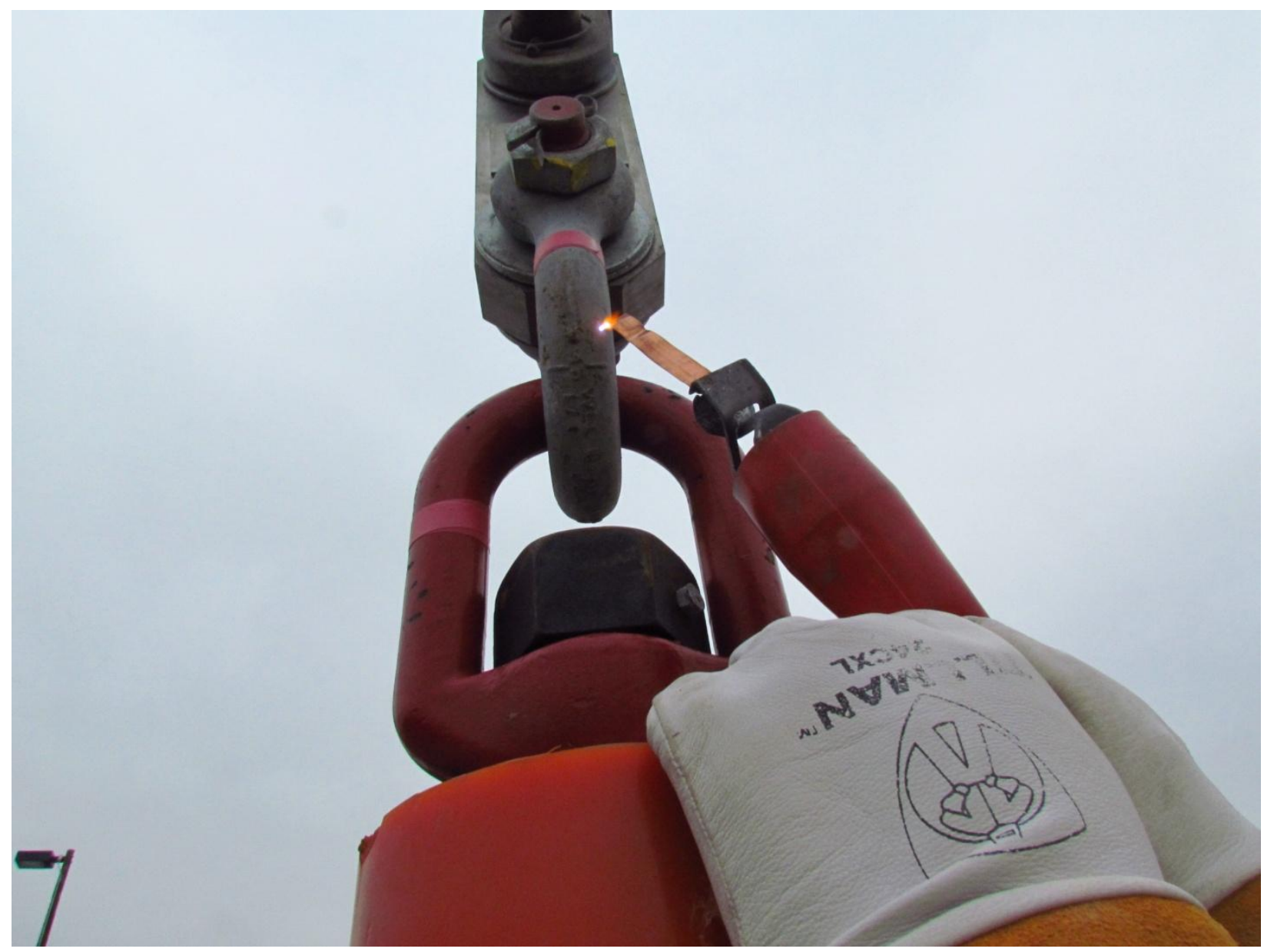

Figure 11. A demonstration of the creation of an arc caused by RF induction currents.

Mr. Russell Ford arranged for a demonstration of the induced RF current issue at the RCEC construction site. This arc was drawn from a conductor closely coupled to the earth beneath the crane hook from the Liebherr crane with approximately $80 \mathrm{ft}$ of cable extended. 


\section{ENDNOTES}

${ }^{1}$ H. J. Hirtzer and Associates, 2150-G Rheem Dr, Pleasanton, CA 94588.

${ }^{2}$ Kane, LLNL, pointed out that CalTrans should have encountered the same problem with construction near the eastern end of the Oakland-Bay Bridge where there are 3 sets of AM broadcast towers close to the toll plaza. CalTrans is apparently using the Hirtzer insulating links with crane operations. Later, in a telephone conversation with Jay Hirtzer, he pointed out that in a number of cases construction at shipping ports, Seattle in particular, had to make use of insulating links. AM broadcast stations make use of the bay flatlands and increased ground conductivity to support the radiation patterns, this places them near shipping ports in many cases.

${ }^{3}$ There is a small error in the polar diagrams in the H \& D Phase 2 report from 6/2011. The calculations show data from 0 to $355^{\circ}$ in azimuth. This is most likely due to a step of $5^{\circ}$ in the computations. In the Phase 1 report there is a gap of data between $355^{\circ}$ and $360^{\circ}$ but the polar plot shows the full 360 azimuth range. In the Phase 2 report the plots are missing the $355^{\circ}$ to $360^{\circ}$ segment and the data. This is minor and there's no difference in the assessment of the results.

${ }^{4}$ In Hatfield and Dawson's first report the electric field was measured at a number of piling locations and are listed in a table (page 3 of 32). At location PR-906, a distance of 748 feet from KFAX tower 1 , a value of $10 \mathrm{~V} / \mathrm{m}$ was measured, the simple computer model resulted in a value of $14 \mathrm{~V} / \mathrm{m}$ and is a reasonable result. Both $\mathrm{KFAX}$ and KTRB contribute to the measured voltage 